\title{
Excessive Formation and Stabilization of Dendritic Spine Clusters in the MECP2-Duplication Syndrome Mouse Model of Autism
}

\author{
Ryan Thomas Ash,, ,2,3,4 Jiyoung Park, ${ }^{2,4}$ Bernhard Suter, ${ }^{4,5,6}$ CHuda Yaya Zoghbi, ${ }^{2,5,6,7,8}$ and \\ (1) Stelios Manolis Smirnakis ${ }^{2,4}$
}

https://doi.org/10.1523/ENEURO.0282-20.2020

${ }^{1}$ Department of Psychiatry and Behavioral Sciences, Stanford University, Stanford, CA 94305, ${ }^{2}$ Department of Neuroscience, Baylor College of Medicine, Houston, TX 77030, ${ }^{3}$ Medical Scientist Training Program, Baylor College of Medicine, Houston, TX 77030, ${ }^{4}$ Department of Neurology, Brigham and Women's Hospital, Harvard Medical School, Boston, MA 02115, ${ }^{5}$ Department of Pediatrics, Texas Children's Hospital and Baylor College of Medicine, Houston, TX 77030, ${ }^{6}$ Department of Molecular and Human Genetics, Baylor College of Medicine, Houston, TX 77030, ${ }^{7} J a n$ and Dan Duncan Neurological Research Institute at Texas Children's Hospital, Houston, TX 77030, and ${ }^{8}$ Howard Hughes Medical Institute, Baylor College of Medicine, Houston, TX 77030

\begin{abstract}
Autism-associated genetic mutations may perturb the balance between stability and plasticity of synaptic connections in the brain. Here, we report an increase in the formation and stabilization of dendritic spines in the cerebral cortex of the mouse model of MECP2-duplication syndrome, a high-penetrance form of syndromic autism. Increased stabilization is mediated entirely by spines that form cooperatively in $10-\mu \mathrm{m}$ clusters and is observable across multiple cortical areas both spontaneously and following motor training. Excessive stability of dendritic spine clusters could contribute to behavioral rigidity and other phenotypes in syndromic autism.
\end{abstract}

Key words: autism; dendritic spine; MECP2; motor cortex; neuroplasticity; structural plasticity

\section{Significance Statement}

The inflexible repetitive behaviors, "insistence on sameness," and at times exceptional learning abilities seen in autism imply a defect in the neural processes underlying learning and memory, potentially affecting the balance between stability and plasticity of synaptic connections in the brain. Here, we report a pathologic bias toward stability of newly formed dendritic spines in the MECP2-duplication mouse model of autism. Enhanced spine stability is mediated entirely by spines aggregating within $10 \mu \mathrm{m}$ of each other, in clusters. Enhanced clustered spine stability is observable in multiple brain areas both at rest and during motor training. The results suggest that some phenotypes of autism could arise from abnormal consolidation of clustered synaptic connections.

\section{Introduction}

It has been proposed that phenotypes of autism spectrum disorder arise from an abnormal imbalance between the stability and plasticity of synaptic connections in the brain (Ramocki and Zoghbi, 2008). Such an imbalance may potentially contribute to the rigid, restricted behavioral repertoire and insistence on sameness seen in

Received June 29, 2020; accepted September 14, 2020; First published November 9, 2020.

The authors declare no competing financial interests. autism (Howlin et al., 2009; Treffert, 2014). Rebalancing synaptic stability and plasticity could provide a therapeutic avenue to promote behavioral flexibility in patients.

Methyl-CpG-binding protein 2 (MeCP2) is an X-linked transcriptional regulator that contributes to the maintenance of neural circuit homeostasis through the activity-

Author contributions: R.T.A., B.S., H.Y.Z., and S.M.S. designed research; R.T.A., J.P., and B.S. performed research; R.T.A., H.Y.Z., and S.M.S. contributed unpublished reagents/analytic tools; R.T.A. and J.P. analyzed data; R.T.A., J.P., B.S., H.Y.Z., and S.M.S. wrote the paper. 
dependent modulation of gene expression and splicing (Lyst and Bird, 2015). Loss of function mutations in MECP2 cause Rett Syndrome, a neurodevelopmental disorder affecting females (Chahrour and Zoghbi, 2007). Mice engineered to overexpress MECP2 at twice normal levels exhibit a neurologic phenotype that falls squarely within the spectrum of autism (Collins et al., 2004; Samaco et al., 2012). They exhibit social avoidance, stereotypies, and behavioral inflexibility that progresses to motor dysfunction, spasticity, and epilepsy (Collins et al., 2004; Na et al., 2012; Samaco et al., 2012; Sztainberg et al., 2015). Patients with genomic duplication of MECP2, identified soon after the description of MECP2-duplication syndrome in mice, demonstrate many similar features highly characteristic of autism (Ramocki et al., 2009, 2010; Peters et al., 2013). The MECP2-duplication mouse is therefore a valuable tool for studying neural circuit phenotypes in autism (Tordjman et al., 2007).

An abnormal upregulation in the spontaneous turnover of pyramidal neuron dendritic spines has been observed across several mouse models of autism including the MECP2-duplication mouse (Chow et al., 2009; CruzMartín et al., 2010; Jiang et al., 2013; Isshiki et al., 2014; Gdalyahu et al., 2015; Ash et al., 2018), while mouse models of Rett syndrome exhibited decreased dendritic spine motility (Landi et al., 2011), suggestive of an abnormal balance between synaptic stability and plasticity. Interestingly, in the fragile $X$ syndrome mouse model, it was found that new spines are less likely to be formed and stabilized in clusters compared with controls (Padmashri et al., 2013; Reiner and Dunaevsky, 2015), which could have interesting implications for abnormal learning and plasticity in autism (Yang et al., 2009; Fu et al., 2012). How other autism-associated mutations affect the spatial cooperativity of spine clusters, i.e., local plasticity-promoting interactions between spines mediated by molecular signaling cascades (Harvey and Svoboda, 2007; Harvey et al., 2008), has not been thoroughly evaluated.

In what follows, we provide evidence for an abnormal increase in the stabilization of cooperatively-formed neighboring dendritic spines in the MECP2-duplication

This work was supported by the Simons Foundation Grant 240069 (to S.M. S.), March of Dimes (S.M.S.), the National Institutes of Health/National Institute of Neurological Disorders and Stroke Grant R01NS057819, the Howard Hughes Medical Institute, and the Intellectual and Developmental Disabilities Research Center at Baylor College of Medicine Grant 1U54HD083092 (Administrative and Neurobehavioral Cores) from the Eunice Kennedy Shriver National Institute of Child Health and Human Development (H.Y.Z.). R.T.A. was supported by the Autism Speaks Weatherstone Fellowship and the Baylor College of Medicine Medical Scientist Training Program.

Acknowledgements: We thank G. Allen, S. Torsky, E. Sztainberg, B. Suter, J. Meyer, A. Palagina, J. Patterson, S. Shen, D. Yu, Shelly Buffington, Mauro Costa-Mattioli, and K. Tolias for technical and theoretical advice on experiments and comments on this manuscript. We also thank $\mathrm{H}$. Lu for the images of mouse coronal brain slices.

Correspondence should be addressed to Stelios Manolis Smirnakis at smsmirnakis@bwh.harvard.edu.

https://doi.org/10.1523/ENEURO.0282-20.2020 Copyright (C) 2021 Ash et al.

This is an open-access article distributed under the terms of the Creative Commons Attribution 4.0 International license, which permits unrestricted use, distribution and reproduction in any medium provided that the original work is properly attributed. syndrome mouse model. Excessive stabilization of spine clusters, but not of isolated spines, occurs in the motor and visual cortex of mutant animals, and is observable both in resting animals and animals repetitively trained on the rotarod motor task.

\section{Materials and Methods}

\section{Animals}

FVB-background MECP2-duplication (Tg1) mice (Collins et al., 2004), were crossed to C57 thy1-GFP-M homozygotes obtained from The Jackson Laboratory, to generate F1C57;FVB MECP2-duplication;thy1-GFP-M mice and thy1-GFP-M littermate controls. Males were used in experiments, to avoid possible changes in turnover related to estrous cycle in females (Alexander et al., 2018). Animals were housed in a 12/12 h light/dark cycle (lights on from 7 A.M. to 7P.M.). All experiments with animals were conducted in accordance with the National Institutes of Health Guidelines for the Care and Use of Laboratory Animals and were approved by the Institutional Animal Care and Use Committee.

\section{Blinding}

Surgeries, imaging, rotarod training, and analyses were performed blind to genotype. Mouse numbers and genotypes were placed in a two-column spreadsheet by a lab member not involved in the experiment or analysis, and MATLAB scripts imported genotypes from this spreadsheet to plot data without unblinding the experimenter to genotypes.

\section{In vivo two-photon imaging}

Surgeries and imaging were performed blind to genotype. At least two weeks before the first imaging session ( $\sim 12$ - to 14-week-old mice), a 3-mm-wide opening was drilled over motor cortex, centered at $1.6 \mathrm{~mm}$ lateral to bregma based on Tennant et al. (2011), and a glass coverslip was placed over the exposed brain surface to allow chronic imaging of neuronal morphology (Mostany and Portera-Cailliau, 2008, 2011). Dendritic spines were imaged using a Zeiss in vivo two-photon microscope with Zeiss $20 \times 1.0$ NA water-immersion objective lens. Highquality craniotomies had a characteristic bright-field appearance with well-defined vasculature and pale gray matter. Under two-photon scanning fluorescent dendrites were reliably clear and visible with low laser power $(<20$ $\mathrm{mW}$ on the pia) and photomultiplier tube voltage.

Only high-quality preparations (low background noise across all time points, less than five-pixel [0.25 $\mu \mathrm{m}]$ motion artifact, and dendrites well isolated from other fluorescent structures) were used in the blinded analysis (Movie 1). GFP-labeled neurons were first imaged at low resolution $[620 \times 620 \mu \mathrm{m}$ field of view (FOV), $0.6 \mu \mathrm{m} /$ pixel in $x y$, $2.5 \mu \mathrm{m} Z$-step size] down to $600-700 \mu \mathrm{m}$ to capture all of the cell's dendritic processes and assay cell subtype by morphology, primary apical bifurcation depth, and soma depth (Holtmaat et al., 2006). The apical dendrites from complex-tufted neurons, the corticospinal neurons projecting to the spinal cord and thalamus in $\mathrm{M} 1$, were selected based on their large highly ramified dendritic trees, 
deep primary apical bifurcation, and thick dendrites, and reimaged at high resolution $(310 \times 310-420 \times 420 \mu \mathrm{m}$ FOV, $0.1 \mu \mathrm{m} /$ pixel, $1 \mu \mathrm{m} Z$-step size) to adequately capture individual dendritic spines. Laser power was maintained under $20 \mathrm{~mW}$ (average $\sim 10 \mathrm{~mW}$ ) during image stack acquisition.

\section{Data inclusion criteria}

Data inclusion was determined by the following indicators of imaging quality: (1) low background noise across all time points; (2) less than five-pixel $(0.25 \mu \mathrm{m})$ motion artifact; and (3) dendrites well isolated from other fluorescent structures. Mice for which imaging quality significantly degraded during the time course of imaging were excluded from the analysis. Otherwise all data were included, and no statistical outliers were excluded.

\section{Analysis of structural plasticity}

Raw $z$ stacks were denoised by a custom polynomial interpolation method. Spine formation, elimination, and stabilization were quantified with a custom MATLAB user interface and ImageJ. Terminal dendrite segments which were well visualized at all time points were chosen for analysis. Sections of dendrite occluded by other fluorescent structures or blood vessels were excluded from the analysis. Because of in vivo two-photon microscopy's relatively poor resolving power in the $z$-axis, only structures protruding laterally along the $x-y$ plane were included in the analysis, following the standard in this field (Holtmaat et al., 2009). For a protrusion to be selected for analysis, it had to project out of the dendritic shaft by at least four pixels $(\sim 0.4 \mu \mathrm{m})$, which corresponds approximately to 2 SDs of the noise blur on either side of the dendritic shaft. Spines were initially identified at one time point, by moving up and down through individual slices in each $z$ stack, and the same region of dendrite was examined at other time points to identify the first (formation) and last (elimination) time that the spine was present. Custom MATLAB routines analyzed the stability/survival of each formed spine. Filopodia, which are rare at the analyzed age, were identified morphologically, based on their long length (usually $>4 \mu \mathrm{m}$ ), curved shape, and lack of a distinct head (Zuo et al., 2005) and excluded from the analysis as in Yang et al. (2009).

\section{Analysis of dendritic spine clustering}

Each spine was classified as either clustered or isolated by calculating the distance to its nearest-neighbor newlyformed stabilized spine (Fu et al., 2012). The difference in clustered spine stabilization rate between MECP2-duplication and wild-type (WT) mice was calculated as a function of cluster distance threshold (maximum distance to nearest co-stabilized spine to be counted as clustered; Fig. $3 A$ ). This difference in clustered spine stabilization increased with increasing cluster distance threshold and plateaued at $9 \mu \mathrm{m}$; we used this threshold to define spine clusters for further analysis.

\section{Spine clustering simulations}

Simulations of formed, stabilized, and baseline dendritic spine locations were generated based on the measured mean and SD of dendritic length, the number of baseline spines and formed spines, and the spine stabilization rate in each genotype. Spine locations were simulated in one dimension. The minimum interspine distance of simulated spines was $0.1 \mu \mathrm{m}$ (the minimum interspine distance observed in the data set); if a spine was $<0.1 \mu \mathrm{m}$ from another simulated spine, it was placed again until it met this criterion. Spine clustering was simulated per animal matched to the number of animals and number of dendrites imaged per animal in the experimental data set. Nearest neighbor analysis was performed on simulated dendritic spines to generate distributions of interspine distances per animal which were then averaged across animals as in Figure 2. The simulation was performed 1000 times to generate bootstrap expected values of interspine distances given random spine localization; 95\% confidence intervals of the simulated results are plotted as maroon (mutant) and gray (WT) error bars in Figure 2.

\section{Motor training}

Mice were imaged in the training and rest conditions in cohorts by litter. All animals within a litter were imaged in either the training or rest condition blind to genotype.

The Ugo Basile mouse rotarod was used for motor training. At least $2 \mathrm{~h}$ after imaging sessions, in the late afternoon, mice were placed on the rotarod, and the rotarod gradually accelerated from 5 to $80 \mathrm{rpm}$ over $3 \mathrm{~min}$. Single-trial rotarod performance was quantified as the time right before falling or holding on to the dowel rod for two complete rotations without regaining footing. A 5- to 10-min rest period occurred between each trial. Four trials were performed per day.

\section{Microstimulation mapping of motor cortex}

After the final imaging session, microstimulation mapping of motor cortex was performed (Fig. 1B) as described previously (Tennant et al., 2011). Under ketamine/ xylazine anesthesia, the coverslip was removed from the craniotomy, and a bipolar stimulating electrode was lowered into the imaged brain region in a $0.5 \times 0.5-\mathrm{mm}$ grid pattern to $\sim 750-\mu \mathrm{m}$ depth (deep L5). Current pulses starting at $10 \mu \mathrm{A}$ (up to $60 \mu \mathrm{A}$ ) were applied until twitching was observed in contralateral muscle groups. Twitching muscle groups were scored as forelimb, hindlimb, face, tongue, or tail. Imaged dendritic arbors were registered with mapped regions using blood vessels as landmarks. All structural plasticity data were acquired from forelimb and hindlimb motor cortex.

\section{Image presentation}

Dendritic spine images are displayed as "best" projection mosaics. Extraneous fluorescence is masked and images are slightly smoothed for illustration purposes only.

\section{Data visualization}

To more rigorously illustrate variability in the data and statistical robustness, data were plotted as GardnerAltman and Cummings estimation plots, as previously 
A Chronic cranial window over motor cortex, 2 months post op

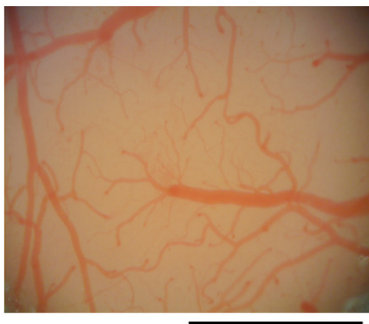

$1 \mathrm{~mm}$
B

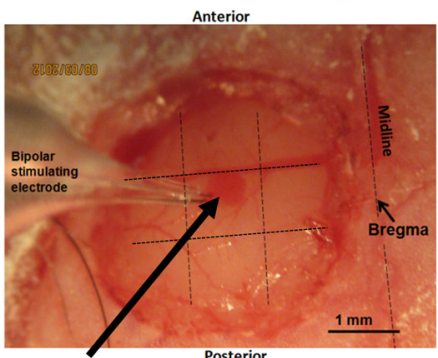

Stimulation site
Confirmation of targeting to motor cortex by electrical stimulation

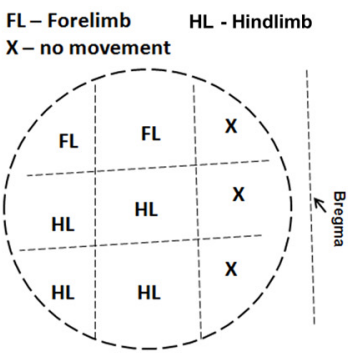

C

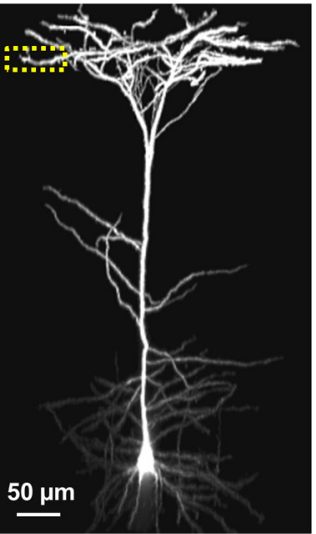

D
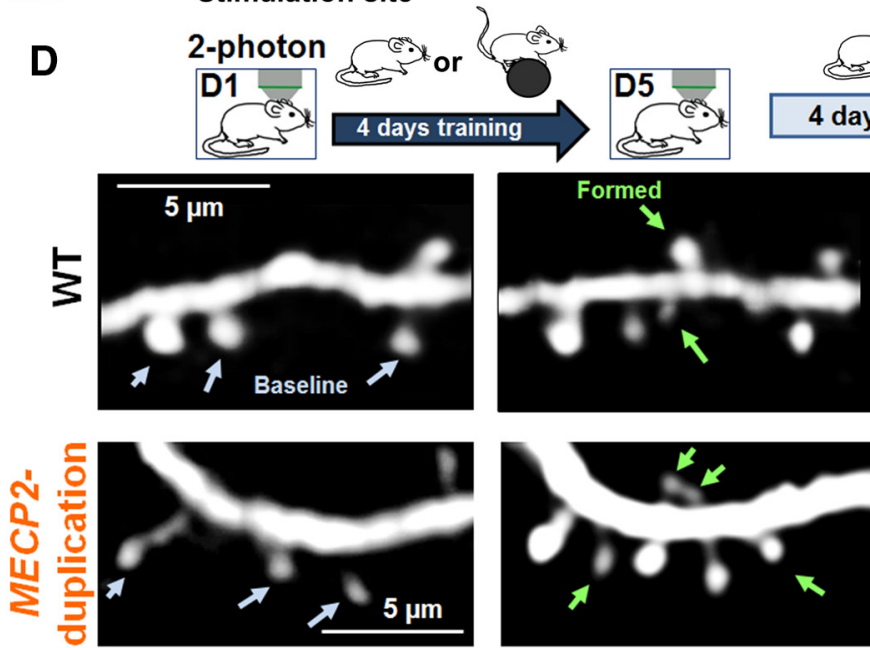

F Spines stabilized

E
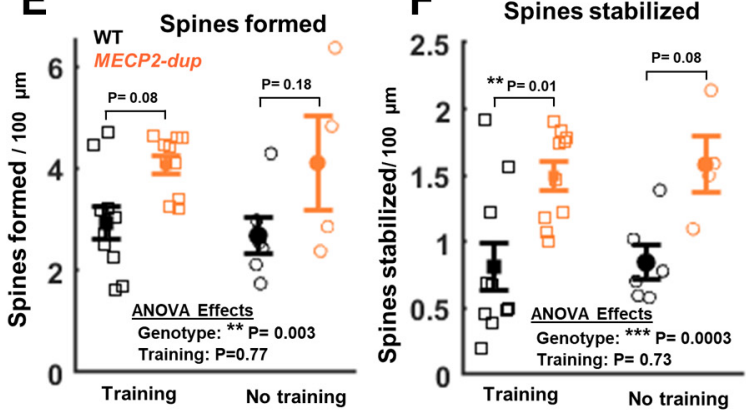

G Spines formed
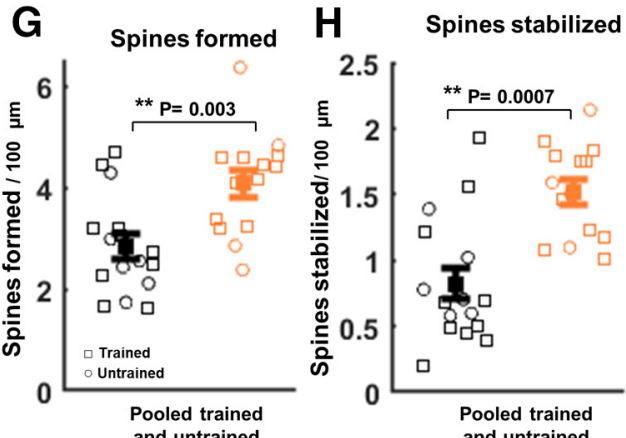

and untrained
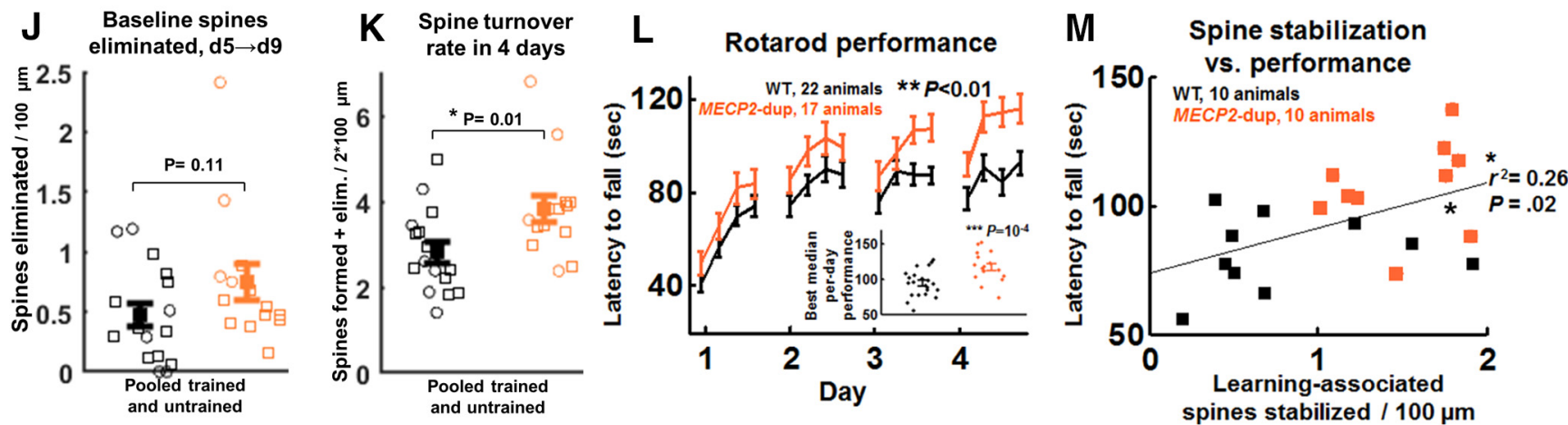

Figure 1. Increased formation and stabilization of dendritic spines in L5 pyramidal neuron apical dendrites of MECP2-duplication mice. $\boldsymbol{A}$, Example brightfield image of chronic cranial windows over M1 at two months postoperative, showing the well-defined vasculature and pale gray matter characteristic of high-quality preparations. $\boldsymbol{B}$, left, Image demonstrating the microstimulation experiment, performed post hoc in experimental mice at the end of imaging. A bipolar stimulating electrode was lowered $\sim 750 \mu \mathrm{m}$ into the window at nine sites in a 1000- $\mu \mathrm{m}$ grid. Right, Example map of motor cortex generated by microstimulation. Forepaw and hindpaw twitches were generated at low currents in all stimulated cortices ( $n=10$ mice), confirming localization to M1. $\boldsymbol{C}$, The dendritic 


\section{continued}

tree of a GFP-labeled L5 complex-tufted pyramidal neuron in area M1 imaged by in vivo two-photon microscopy. Apical tuft terminal dendrites are targeted for time-lapse imaging (yellow box). $\boldsymbol{D}$, Experiment paradigm: sample images of dendritic segments imaged at baseline (left), $4 \mathrm{~d}$ later (middle), and $8 \mathrm{~d}$ later (right). Some mice were trained on the rotarod daily while others were left to rest in the cage between D1 and D5. Top, WT controls. Bottom, MECP2-duplication animals. White arrows point to spines present at baseline, green to newly-formed spines, light-green to stabilized spines, and pink to non-stabilized spines. $\boldsymbol{E}$, Spines formed per $100 \mu \mathrm{m}$ with and without motor training in terminal dendritic branches of MECP2-duplication animals (orange, training: $n=10$ animals, 300 spines formed, 82 dendritic branches; no training: $n=4$ animals, 56 spines formed, 27 dendritic branches) and WT littermate controls (black, training: $n=10$ animals, 276 spines formed, 99 dendritic branches; no training: $n=6$ animals, 42 spines formed, 35 dendritic branches). Squares and circles depict individual data points for trained and untrained animals, respectively. Effect of genotype: ${ }^{* \star} p=0.003, F_{(1,26)}=10.3$; effect of training: $p=0.77$; interaction: $p=0.7$; two-way ANOVA across animals); $p$ values in plot show Tukey-corrected pairwise ANOVA comparisons. $\boldsymbol{F}$, Newly-formed spines stabilized per $100 \mu \mathrm{m}$ in each genotype. Effect of genotype: ${ }^{* \star \star} p=0.0003, F_{(1,26)}=17$; training: $p=0.7$; interaction: $p=0.88 ; p$ values in plot show Tukey-corrected pairwise ANOVA comparisons. G-K, Dendritic spines formed, stabilized, and eliminated, and overall spine turnover rate in L5 apical dendritic arbors with data pooled between trained and untrained animals, in MECP2-duplication mice (orange: $n=14$ animals, 356 spines formed, 109 dendritic branches) and WT littermate controls (black: $n=16$ animals, 318 spines formed, 134 dendritic branches). Squares and circles depict individual data points for trained and untrained animals, respectively. G, Spines formed per $100 \mu \mathrm{m}$, ${ }^{\star \star} p=0.003$, Mann-Whitney $U$ test. $\boldsymbol{H}$, Newly-formed spines stabilized per $100 \mu \mathrm{m},{ }^{* * *} p=0.0007$. $\boldsymbol{I}$, Baseline spines eliminated between experiment days 1 and $5, p=0.17$. , baseline spines eliminated between experiment days 5 and $8, p=0.12$. $K$, Overall spine turnover rate (spines formed + spines eliminated $/ 2 \times$ total dendritic length) in $4 \mathrm{~d}$ (from day 1 to day 5 ), ${ }^{*} p=0.01$. $L$, Mean per-trial rotarod performance (time spent on the accelerating rotarod before falling) across animals in MECP2-duplication animals (orange, $n=17$ ) and WT controls (black, $n=22$ ). This panel contains a larger sample size than other panels, because mice excluded from imaging analysis because of poor imaging quality but who still underwent rotarod training were included; ${ }^{* *} p=0.009$, effect of genotype, $F_{(1,37)}=$ 7.6, repeated-measures ANOVA. Effect of time: $p<0.0001, F_{(15,37)}=29.8$; interaction: $p=0.47, F_{(15,37)}=0.99$. $\boldsymbol{M}$, Scatter plot of learning associated spines that stabilized versus rotarod performance per animal, in imaged MECP2-duplication mice (orange squares) and WT controls (black squares); ${ }^{*} p<0.05, r^{2}=0.26, n=20$ mice pooled across genotypes, Pearson correlation, Student's $t$ test. Error bars indicate mean \pm SEM. See Extended Data Figure 1-1 for visualization of data as estimation plots with bootstrapestimated differences between groups (see Materials and Methods).

shown (Bernard, 2019; Calin-Jageman and Cumming, 2019; Ho et al., 2019). Raw data were exported to https:// www.estimationstats.com/, and graphs were generated. Bootstrap sampling distributions were generated with five thousand bootstrap samples; bootstrap confidence intervals were bias-corrected and accelerated.

\section{Statistical tests}

Statistical significance between samples were assessed by two-way ANOVA or Mann-Whitney $U$ test, as noted, using MATLAB. All results are reported as mean \pm SEM, unless otherwise noted.

\section{Results}

\section{Increased dendritic spine stabilization in MECP2- duplication mice}

We employed in vivo two-photon microscopy (Holtmaat et al., 2009) in primary motor cortex (M1) to measure changes in dendritic spine structural plasticity in the $M E C P 2-d u p l i c a t i o n$ mouse in vivo. Chronic cranial windows were implanted over M1 in MECP2-duplication mice and littermate controls (Fig. 1A,B). Apical dendrites from GFP-expressing (Feng et al., 2000) L5 pyramidal neurons in area M1 (Grimsley et al., 2013) were targeted for imaging (Fig. 1C; Movie 1; Holtmaat et al., 2009). Spine analysis was performed on terminal dendritic branches of the apical tuft of these neurons. Imaging and analysis were performed blind to genotype (see Materials and Methods). Correct targeting to area M1 was confirmed by electrical microstimulation after the final imaging session (Fig. 1B; Tennant et al., 2011). We first identified baseline spines, then animals either rested in their cage or were trained on the rotarod task (four trials per day) for $4 \mathrm{~d}$ (Fig. 1D). On the fifth day, we imaged the dendrites again to identify new spines formed. Following four more days of rest (the time frame of spine stabilization), dendrites were once again imaged to identify the new spines that stabilized. The follow-up imaging time point was chosen in line with prior studies showing that the vast majority of newly formed dendritic spines, which persist for at least $4 \mathrm{~d}$, form an electron-microscopy-verified synapse (Knott et al., 2006).

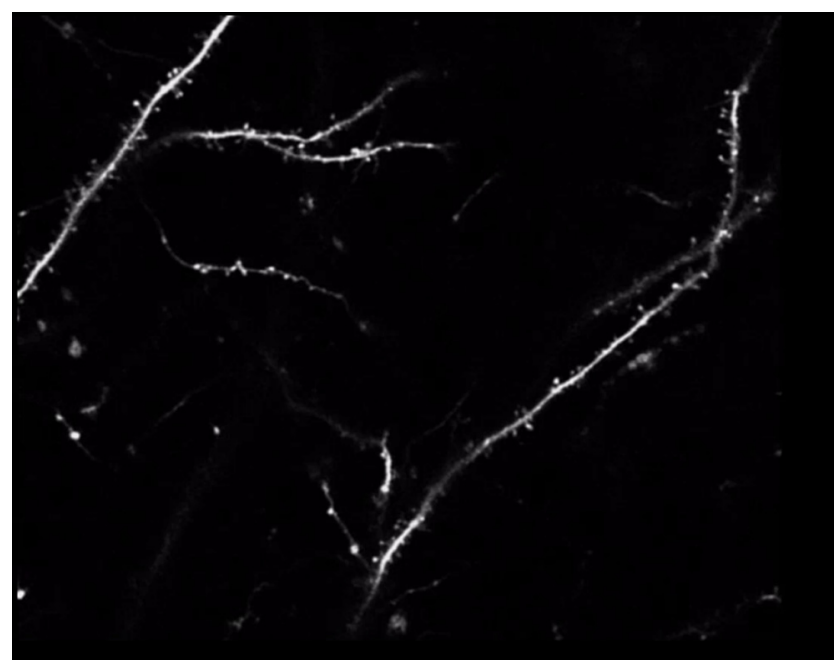

Movie 1. Example $z$ stack of raw data acquired by in vivo structural imaging, demonstrating characteristic sparse, brightly fluorescent, L5 pyramidal neuron dendrites with clearly resolvable dendritic spines. [View online] 
We found that $\sim 30 \%$ more spines were formed in MECP2-duplication mice (Fig. $1 E$, orange) WT littermates (black; $p=0.002, F_{(1,26)}=11.3$, effect of genotype, two-way ANOVA; Fig. 1E). Similar numbers of spines were formed in trained versus untrained animals in both genotypes $(p=0.8$, $F_{(1,26)}=0.04$, effect of training; Fig. $1 E$ ), presumably because of the weak training paradigm employed relative to (Yang et al., 2009; Liston et al., 2013; Frank et al., 2018), which was selected to optimize the behavioral difference in learning between mutant and control mice (Collins et al., 2004). Almost twice as many new spines were stabilized in MECP2-duplication mice compared with controls $(1.5 \pm 0.1$ vs $0.8 \pm 0.2$ spines $/ 100 \mu \mathrm{m}, p=0.0002, F_{(1,26)}=17.9$, effect of genotype, two-way ANOVA; Fig. 1F), an effect that was observable in both trained and untrained animals and also did not vary significantly with training (effect of training: $p=0.7$ ). Given the lack of effect of rotarod training on spine formation and stabilization for the training paradigm we selected, data from trained and untrained animals were pooled for the remainder of this report. Analyzed dendritic lengths were similar between genotypes ( $p=0.9$, WT: $78 \pm 36 \mu \mathrm{m}$, MECP2-duplication: $80 \pm 34 \mu \mathrm{m}$, median $\pm \mathrm{SD}$ ).

With data pooled, we confirmed that significantly more spines were formed and stabilized in MECP2-duplication mice versus WT [formation: $4.1 \pm 0.2$ vs $2.8 \pm 0.3$ spines/ $100 \mu \mathrm{m}, p=0.003$, Mann-Whitney $U$ test, $n=16$ WT animals, $n=14$ MECP2-duplication animals (Fig. 1G); stabilization: $1.5 \pm 0.1$ vs $0.8 \pm 0.1$ spines $/ 100 \mu \mathrm{m}, p=0.0007$ (Fig. $1 H)$ ]. With data pooled, the study was well powered to detect significant differences in formation $(1-\beta=$ $0.994)$ and stabilization $(1-\beta=0.9991)$ in MECP2-duplication mice. Data are visualized as estimation plots with bootstrap-estimated differences between groups as in $\mathrm{Ho}$ et al. (2019) in Extended Data Figure 1-1 (see Materials and Methods). These results indicate a pronounced increase in the formation and stabilization of dendritic spines in mutant animals.

There was a nonsignificant trend toward increased baseline spine elimination rate in MECP2-duplication mice versus littermate controls across the $8 \mathrm{~d}$ of imaging (Fig. $1 /, J$, although our study was not statistically powered to detect this difference given variability in WT animals $(1-\beta=0.60$ for $\mathrm{d} 1 \rightarrow 5 ; 1-\beta=0.64$ for $\mathrm{d} 5 \rightarrow 9$ ). Overall, spine turnover rates (spines formed + spines eliminated in $4 \mathrm{~d}$ per $\left.2^{*} 100 \mu \mathrm{m}\right)$ were significantly increased in mutants versus WT $(p=0.01$, Mann-Whitney $U$ test, $1-\beta=0.9445$; Fig. $1 K)$. For estimation plot visualizations of these data, see also Extended Data Figure 1-1C-E. These results cohere with our previous findings of increased spine turnover rate and spine elimination in the somatosensory cortex of MECP2-duplication mice (Jiang et al., 2013). Spine densities were similar between the three- to four-month-old MECP2-duplication mice and WT controls we imaged (WT: $0.2 \pm 0.01$ spines per micrometer; MECP2-duplication: $0.23 \pm 0.1$ spines per micrometer), also in agreement with results from somatosensory cortex at that age (Jiang et al., 2013). Previous longitudinal imaging from somatosensory cortex in MECP2-duplication mice found that spine density decreases gradually with age in these animals (Jiang et al., 2013), suggesting that the increase in stabilization of newly formed spines we report here (Fig. $1 G$ ) is not sufficient to compensate for the overall increase in spine turnover rate (Fig. 1/-K), leading to a net decrease in spine density over time.

MECP2-duplication mice performed significantly better on the rotarod as has been previously reported (Collins et al., 2004; $p=0.01$; WT: $n=22$ animals, MECP2-duplication: $n=17$; repeated-measures ANOVA; Fig. $1 K)$. The median best per-day performance was $117 \pm 5 \mathrm{~s}$ for MECP2-duplication mice and $94 \pm 4 \mathrm{~s}$ for controls ( $p=10^{-4}, t$ test across animals). Spine formation, stabilization, and elimination did not correlate strongly with motor performance in trained animals within either genotype (all $p>0.5$, linear regression), likely because of the fact that our training paradigm was weak (Yang et al., 2009). However, when data were pooled across genotypes, there was a significant correlation between spine stabilization and rotarod performance $\left(r^{2}=0.26, p=0.02\right.$, Pearson correlation, Student's $t$ test; Fig. 1M). Given that prior studies (Yang et al., 2009; Liston et al., 2013) have clearly shown that higher spine stabilization rate correlates with enhanced behavioral performance with rotarod training, this suggests that the increased rate of spine stabilization observed in MECP2-duplication animals may in part explain the higher rotarod performance of mutants versus controls.

\section{Increased stabilization of dendritic spine clusters in MECP2-duplication mice}

We next examined the spatial distribution of dendritic spines forming in motor cortex (Morita, 2009; Fu et al., 2012; Kastellakis et al., 2015; Frank et al., 2018). We observed that in MECP2-duplication mice newly formed spines were often stabilized in pairs or triplets along the dendrite (Fig. 1D, bottom right panel). We binned stabilized spines by their proximity to other newly formed spines and detected a dramatic increase in synaptic clustering in MECP2-duplication mice that was not present in WT littermates (Fig. 2A). Almost three times as many spines were stabilized within $5 \mu \mathrm{m}$ of another new spine in MECP2-duplication mice compared with WT controls (7.2 \pm 0.8 vs $2.6 \pm 0.7$ spines $/ 1000 \mu \mathrm{m}, p<0.0001, n=14$ MECP2-duplication, 16 WT animals, ANOVA with Tukey correction for multiple comparisons). Beyond 10- $\mu \mathrm{m}$ interspine distance, similar numbers of spines were stabilized in both genotypes, indicating that the increased spine stabilization observed in MECP2-duplication mice (Fig. $1 F, G$ ) is mediated almost exclusively through excessive stabilization of dendritic spine clusters (Fig. 2A).

Dendritic spine locations were simulated matched to measured spine formation and stabilization rates in mutants and controls and the number of analyzed dendrites and animals, to generate bootstrap confidence intervals of expected spine distributions given no spatial inhomogeneity in formation/stabilization (95\% confidence intervals; Fig. $2 A, B$, gray and maroon error bars; for details, see Materials and Methods). Comparing simulated spine distributions to experimental data showed that increased clustered spine stability was not a by-product of the 
A A Clustering of stabilized spines

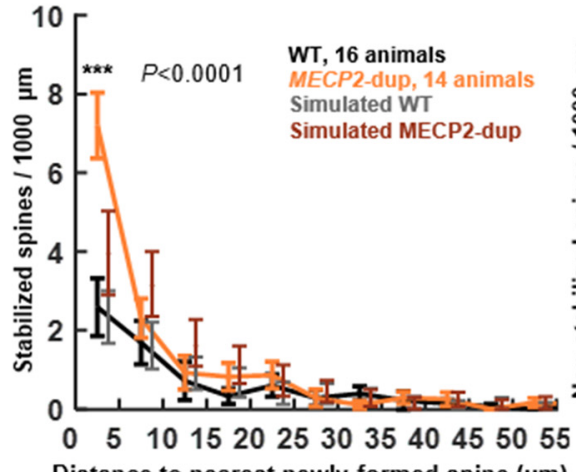

Distance to nearest newly-formed spine $(\mu \mathrm{m})$
B Clustering of non-stabilized spines

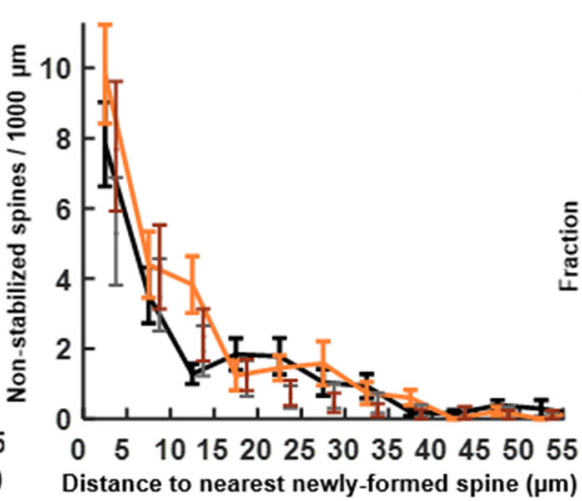

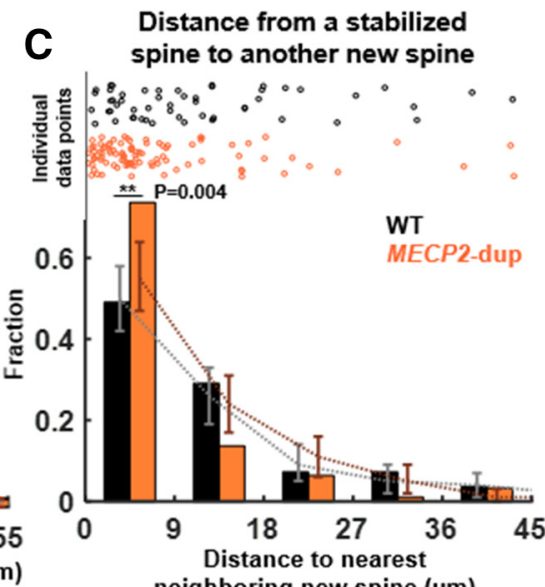

Distance from a stabilized spine to another new spine

neighboring new spine ( $\mu \mathrm{m})$

\section{Distance from a stabilized
spine to a baseline spine}
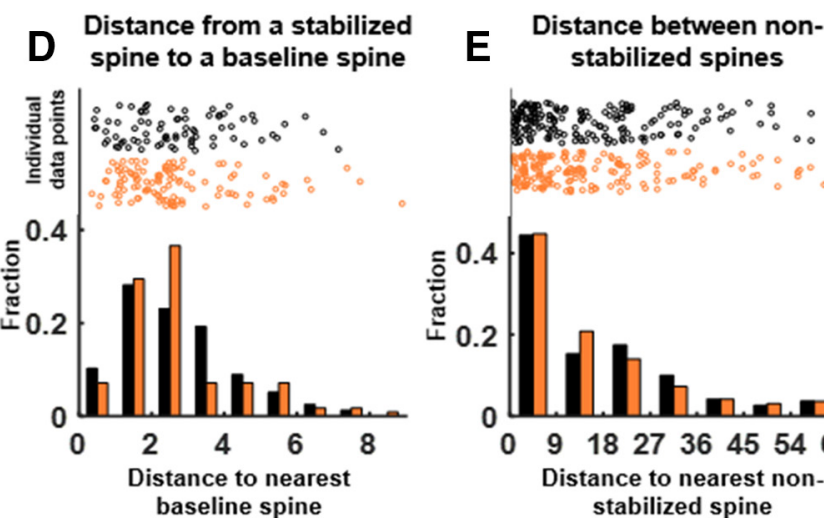

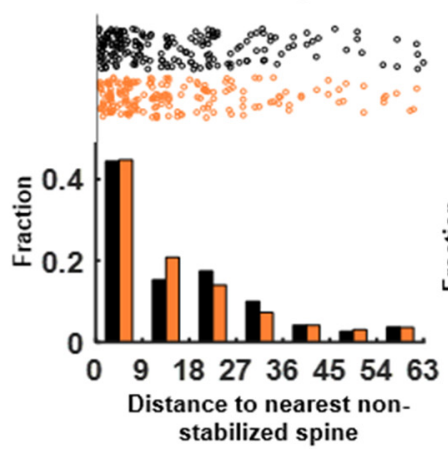

F $\begin{gathered}\text { Distance from a non- } \\ \text { stabilized to a baseline spine }\end{gathered}$
Distance between baseline spines
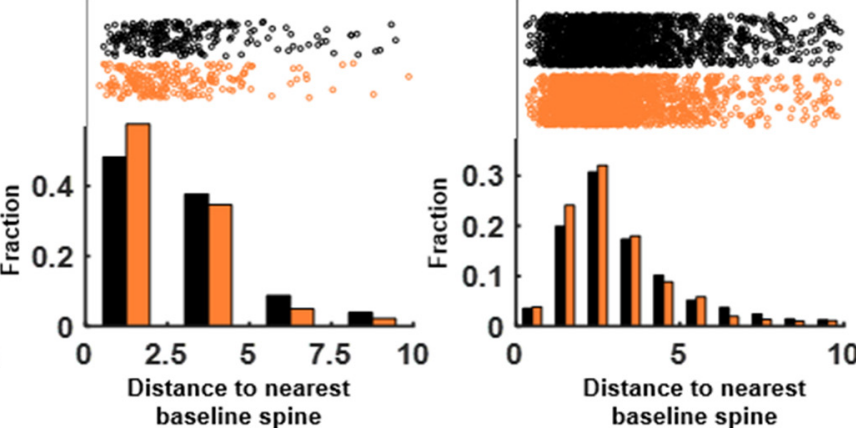

Figure 2. Increased stabilization of dendritic spine clusters in MECP2-duplication mice. $\boldsymbol{A}$, Mean number of new spines that stabilized per $1000 \mu \mathrm{m}$, binned by distance to the nearest neighboring new spine. Bin size $=5 \mu \mathrm{m}$; ${ }^{\star * *} p<10^{-7}$, two-way ANOVA with Tukey correction for multiple comparisons, $F_{\text {genotype(1,29) }}=34.3, F_{\text {clusterbin(12,29) }}=14.7, F_{\text {genotype } \times \text { clusterbin(12,29) }}=7.6, n=16 \mathrm{WT}, 14$ MECP2-duplication animals. Gray and maroon error bars show mean $\pm 95 \%$ confidence intervals of spine distributions predicted by simulation based on measured spine formation and stabilization rates. $\boldsymbol{B}$, Mean number of spines that formed but did not stabilize per $1000 \mu \mathrm{m}$, binned by distance to the nearest neighboring new spine. Gray and maroon error bars depict simulation results. $\boldsymbol{C}$, Histogram of the distance to the nearest neighboring newly formed spine (whether stabilized or non-stabilized) for each stabilized spine, in MECP2duplication (orange) and WT (black) mice. Individual data points for each spine are shown at the top; ${ }^{*} p=0.004$, Fisher exact test. Gray and maroon error bars depict mean $\pm 95 \%$ confidence intervals of the estimated distribution of distances between stabilized spines simulated from the number of spines formed and stabilized per micrometer in each genotype (see Materials and Methods). Differences in overall spine formation and stabilization in mutants do not explain the increase in clustered spine stabilization between mutant and WT ( $p<0.001$, MECP2-duplication data vs MECP2-duplication simulation, boot strap comparison). $\boldsymbol{D}$, Histogram of distances from each stabilized spine to the nearest preexisting baseline spine. $\boldsymbol{E}$, Histogram of nearest-neighbor distances between all non-stabilized new spines. $\boldsymbol{F}$, Histogram of distances from each non-stabilized spine to the nearest preexisting baseline spine. $\boldsymbol{G}$, Histogram of nearest-neighbor distances between baseline spines. None of the distributions in $\boldsymbol{D}-\mathbf{G}$ showed significant differences. Error bars indicate mean \pm SEM .

overall increase in spine formation or stabilization observed in mutants. Non-stabilized spines occurred in clusters at similar rates between WT mice and MECP2duplication mice (Fig. 2B).

Plotting the distribution of interspine distances between each stabilized spine and its nearest neighbor newly formed spine confirmed an upregulation in the number of clustered stabilized spines in mutants compared with WT controls $(p=0.004$, Fisher exact test; Fig. $2 C)$. The distance from each stabilized spine to the nearest baseline spine (Fig. 2D) did not differ significantly between MECP2-duplication mice and controls $(p>0.05$, Fisher exact test). Newly formed non-stabilized spines (Fig. 2E,F) and baseline spines (Fig. 2G) also demonstrated spatial distributions similar to WT.

New spines were not more likely to be stabilized in clusters than chance in WT mice (Fig. 2A-C, compare data black lines to simulation gray lines), indicating that cooperative spine stabilization was specific to mutants under our experimental conditions. Separately analyzing data from trained and untrained animals did not show a significant effect of training on spine clustering in mutants or controls (effect of training: $p=0.6, F=0.29$; genotype $\times$ training interaction: $p=0.9, F=0.01$; two-way ANOVA), which we attribute either to the type or weak intensity of training employed (Fu et al., 2012).

To further quantify clustered-spine stabilization in MECP2duplication mice, we categorized each stabilized spine as clustered $(<9 \mu \mathrm{m}$ to nearest neighboring new spine; Fig. $3 A, B$ ) or isolated ( $>9 \mu \mathrm{m}$ to nearest neighboring new spine). Nine micrometers was chosen as a distance threshold for defining clusters because the difference in clustered-spine stabilization between mutants and WT plateaued at this 
A Classification of spines as clustered or isolated

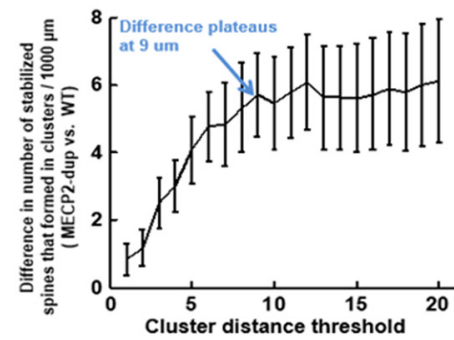

C

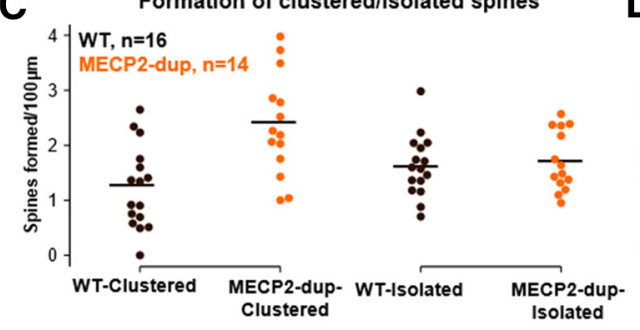

B

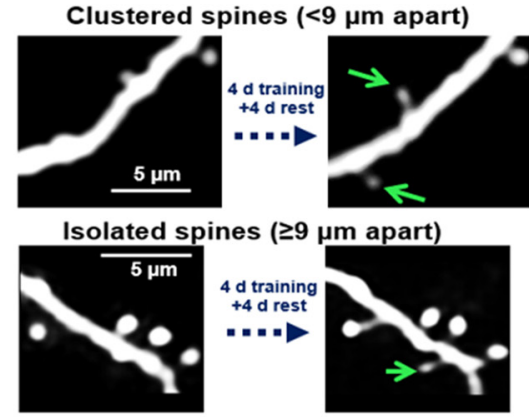

D Stabilization of clustered/isolated spines

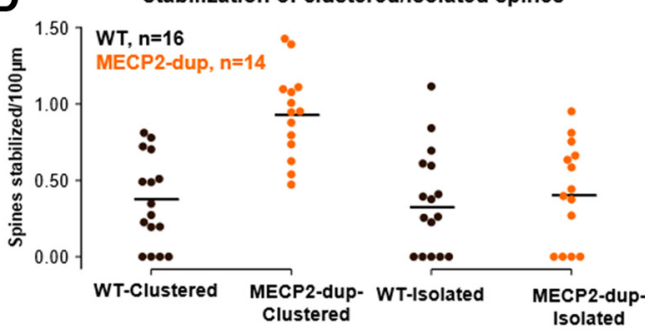

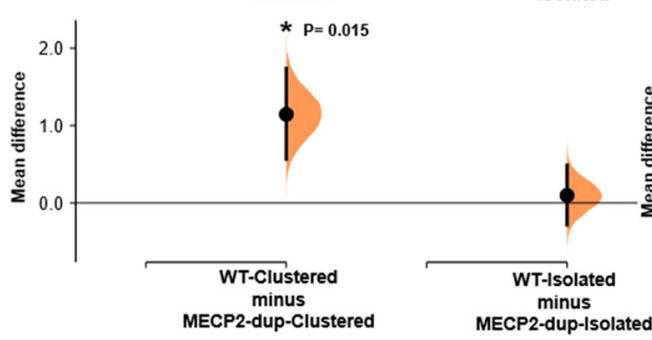

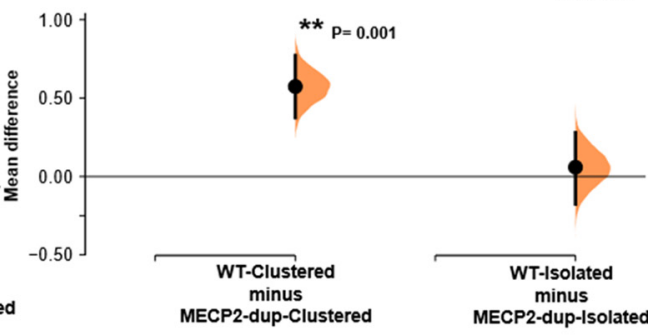

E Percentage of new clustered/isolated spines stabilized

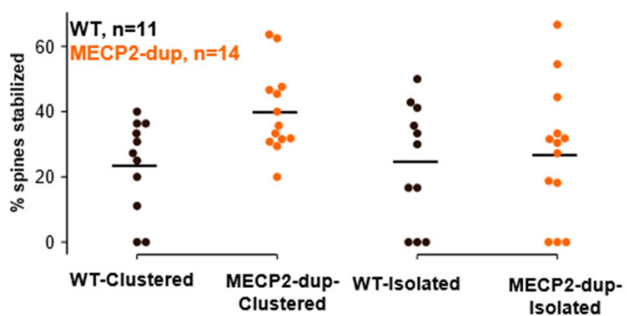

$\mathbf{F}$
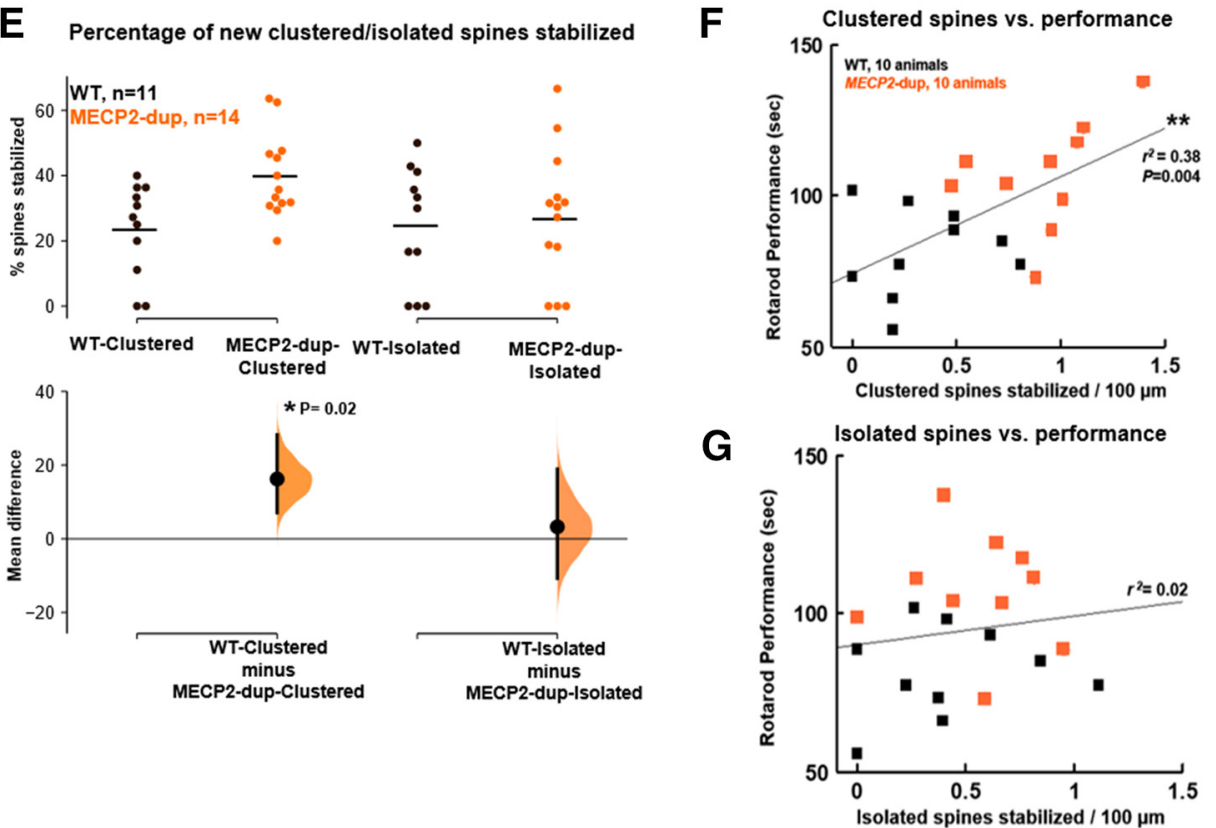

Figure 3. Differential stabilization of clustered and isolated spines in MECP2-duplication mice. A, Determination of cluster distance threshold. Increase in clustered spine stabilization in mutants versus WT littermates, plotted as a function of the cluster distance threshold applied (i.e., the maximum distance to another newly formed spine to be categorized as clustered). Error bars represent the summed SEM from both genotypes. The difference in clustered spine stabilization between genotypes increases with increasing cluster distance threshold leveling off to a plateau at $\sim 9 \mu \mathrm{m} ; 9 \mu \mathrm{m}$ was therefore chosen for further analysis, and this agrees with the range of spine consolidation cooperativity shown in vitro by Harvey and Svoboda (2007) and in vivo by Fu et al. (2012). B, top, Example of stabilized clustered spines. Bottom, Example of an isolated stabilized spine. $\boldsymbol{C}-\boldsymbol{E}$, Clustered and isolated spines formed per $100 \mu \mathrm{m}$, stabilized per $100 \mu \mathrm{m}$, and percentage stabilized from MECP2-duplication mice (orange) and WT (black), visualized as a Cumming estimation plot, as in Ho et al. (2019). Raw data are plotted on the upper axes (dots depict individual data points, 
continued

horizontal lines depict means). The lower axes show the bootstrapped distribution (light orange) and 95\% confidence interval (vertical error bar) of the estimated mean difference between the two groups. Data were pooled across trained and untrained animals. $\boldsymbol{C}$, Clustered and isolated spines formed per micrometer in each genotype; * $p=0.015$, Mann-Whitney $U$ test. $\boldsymbol{D}$, clustered and isolated spines stabilized per micrometer in each genotype; ${ }^{\star \star} p=0.001$. $\boldsymbol{E}$, Percentage of newly formed clustered and isolated spines that stabilized. Animals that formed fewer than four clustered spines were excluded from the analysis because the percentage measure shows large variability with small numbers of spines; $n=11 \mathrm{WT}, n=14 \mathrm{MECP} 2$-duplication mice; ${ }^{*} p=0.02$. $\boldsymbol{F}$, Stabilization of dendritic spine clusters correlates with enhanced rotarod performance in MECP2-duplication mice (orange) and WT controls (black); ${ }^{* *} p=0.004, r^{2}=0.38, n=20$ mice pooled across genotypes, Pearson correlation, Student's $t$ test. $\mathbf{G}$, Stabilization of isolated new spines does not correlate with rotarod performance $\left(r^{2}=0.02, p=0.55\right)$, suggesting that clustered spine stabilization is a better predictor of behavioral performance. For visualization of data as mean \pm SE with individual data points plotted as circles (untrained) and squares (trained), see Extended Data Figure 3-1.

threshold (Fig. 3A; see Materials and Methods); this distance also matches a known form of cooperative synaptic clustering observed in vitro (Harvey and Svoboda, 2007). This analysis further confirmed the upregulation in clustered but not isolated spine formation ( $p=0.01$; Fig. $3 C$ ) and stabilization $(p=0.001$; Fig. $3 D)$ in MECP2-duplication mice compared with controls. Similar to what was observed for overall spine formation and stabilization, analyzing trained and untrained animals separately showed no effect of training on clustered spine formation and stabilization (formation: ANOVA effect of training: $p=0.72$, effect of genotype: $p=0.0008$, interaction: $p=0.3$; stabilization: ANOVA effect of training: $p=0.59$, effect of genotype: $p<0.00,001$, interaction: $p=0.9$ ). Interestingly, clustered new spines were almost twice as likely to be stabilized in MECP2-duplication mice $(40 \pm 4 \%$ of clustered spines; Fig. $3 E$ ) compared with WT $(23 \pm 4 \%$ of clustered spines, $p=0.02$, Mann-Whitney $U$ test), while isolated spines showed similar rates of consolidation between genotypes (Fig. 3E). Importantly, similar statistically significant results were observable for a range of cluster thresholds (from 5 to $12 \mu \mathrm{m})$. Mean \pm SE error bars with individual data points plotted as circles (untrained) and squares (trained) are shown for these data in Extended Data Figure 3-1 for completeness.

Previous work has shown that mice with elevated clustered dendritic spine plasticity are superior learners (Frank et al., 2018). Indeed, when pooling animals from both genotypes, we found that animals that formed and stabilized larger numbers of new spine clusters (typically MECP2-duplication mice) performed better on the rotarod $\left(r^{2}=0.38, p=0.004\right.$; Student's $t$ distribution; Fig. 3F). In contrast, stabilization of isolated new spines did not correlate with enhanced performance $\left(r^{2}=0.02, p=0.55\right.$; Fig. $3 G)$. These results suggest that abnormal clustered-spine stabilization could contribute to enhanced procedural memory consolidation in MECP2-duplication mice.

We next checked to see whether changes in clustered spine stabilization were observable in other cortical areas. We therefore performed the same imaging experiment in the visual cortex of mutants and controls (Fig. 4). Remarkably, although overall spine formation and stabilization were not significantly increased in $M E C P 2$-duplication mouse visual cortex (Fig. 4A,B), clustered spine formation (Fig. $4 C$ ) and stabilization (Fig. $4 D$ ) were also significantly upregulated in this area in mutants. As observed in motor cortex, isolated spine stabilization was similar between mutants and controls in primary visual cortex (V1; Fig. 4E). These data indicate that excessive clustered spine stabilization is driving spine consolidation in multiple cortical areas in MECP2-duplication mice.

\section{Discussion}

Abnormally increased dendritic spine turnover has been observed in several autism mouse models (Chow et al., 2009; Jiang et al., 2013; Isshiki et al., 2014; Gdalyahu et al., 2015), including the MECP2-duplication, neuroligin-3, $15 \mathrm{q}$ duplication, PTEN, and CNTNAP2 mice, suggesting they share a deficit in the balance between structural synaptic plasticity and stability.

We found that $\sim 33 \%$ more new spines are formed after $4 \mathrm{~d}$ in apical tufts of MECP2-duplication mouse L5 pyramidal neurons compared with littermate controls. These newly-formed spines are $\sim 40 \%$ more likely to be stabilized compared with controls, leading to almost twice as many new spines stabilized in MECP2-duplication animals. Remarkably, the increased dendritic spine stabilization we observed in MECP2-duplication mice was mediated entirely by spines formed in $9-\mu \mathrm{m}$-long clusters. This clustering was specific to newly formed spines and was not observable in the spatial distribution of non-stabilized spines or baseline spines, nor was it observable in the distance between new spines and baseline spines, suggesting that cooperativity is specific to newly formed spines.

\section{Elevated clustered spine stabilization and increased spine turnover: implications for synaptic homeostasis}

Although newly formed dendritic spine clusters were more stable in MECP2-duplication mice (Fig. 3D), overall dendritic spine turnover was elevated (Figure $1 K$; and spine elimination also trended toward higher values in mutants; Fig. 1/,J). These latter results agree with our prior studies in the somatosensory cortex of MECP2-duplication mice showing increased dendritic spine turnover and a net increase in spine elimination, with higher spine densities in young mice falling gradually with age to plateau at a lower spine density compared with control in older animals ( $>16$ weeks). Therefore, there are two plasticity processes operating differently in MECP2-duplication mice: increased stabilization of clustered spines and increased overall spine turnover, which presumably serve to somewhat balance each other. It is interesting to speculate that one of these processes may reflect the primary defect, while the other could serve as a compensatory mechanism. Elevated spine turnover may explain why we do not observe an overall increase in clustering of "baseline spines," i.e., spines detected on the first day of observation (Fig. 2G). Follow-up experiments will be important to assess dendritic spine consolidation over longer time scales in the future. 
A

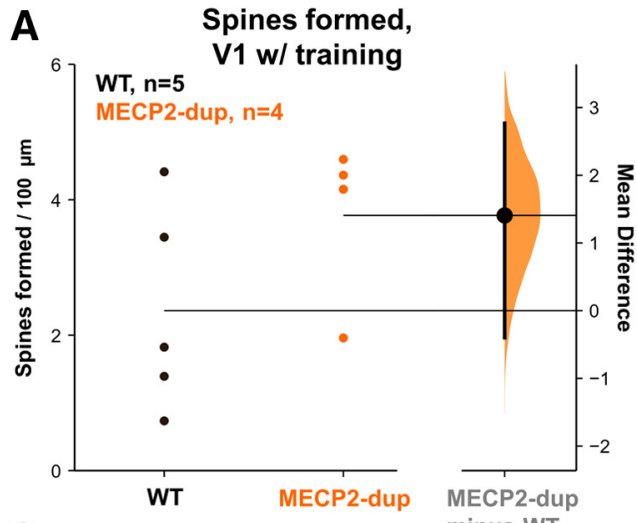

C
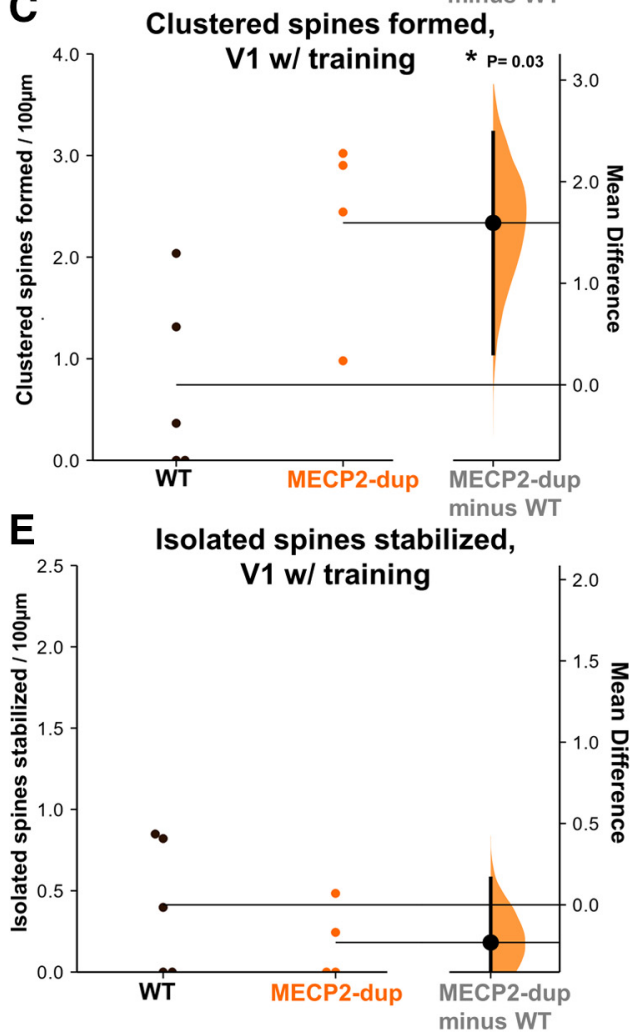

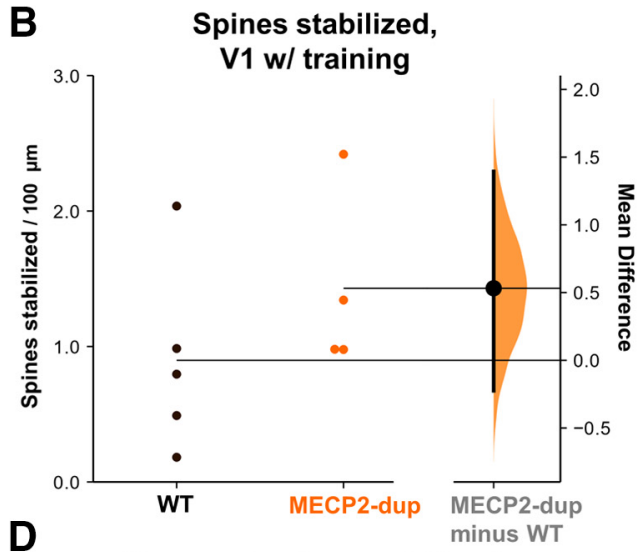

Clustered spines stabilized,

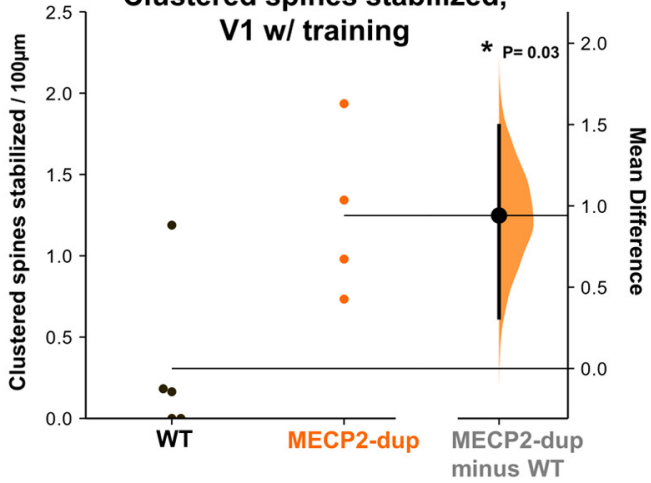

Figure 4. Dendritic spine structural plasticity in visual cortex (V1) in MECP2-duplication mice and littermate controls. $\boldsymbol{A}-\boldsymbol{E}$, Spine formation and stabilization in visual cortex. Orange, MECP2-duplication. Data are plotted as a Gardner-Altman estimation plot to visualize the results using estimation statistics as in Ho et al. (2019). The left axis of each panel shows individual data points for WT (black) and MECP2-duplication (orange) animals. The right axis shows the bootstrapped distribution (light orange) and $95 \%$ confidence interval (vertical black line) of the estimated difference between the two groups. WT: $n=5$ mice, 60 spines formed, 33 branches; MECP2-duplication: $n=4$ mice, 60 spines formed, 31 branches. All animals in this condition were trained on the rotarod. $\boldsymbol{A}$, New spines formed between D1 and D5 per $100 \mu \mathrm{m}$ in visual cortex in each genotype. $\boldsymbol{B}$, New spines stabilized (still present at D9) per $100 \mu \mathrm{m}$ in visual cortex in each genotype. C, Clustered spines formed per $100 \mu \mathrm{m}$ in visual cortex in each genotype; ${ }^{*} p=0.03$, Mann-Whitney $U$ test. $\boldsymbol{D}$, Clustered spines stabilized per $100 \mu \mathrm{m}$ in visual cortex in each genotype; ${ }^{*} p=0.03$. $\boldsymbol{E}$, Isolated spines stabilized per $100 \mu \mathrm{m}$ in each genotype. Error bars indicate mean \pm SEM.

\section{Impact of increased synaptic clustering}

An increase in clustered spine stabilization can potentially have important functional implications (Kastellakis et al., 2015; Gökçe et al., 2016; Weber et al., 2016). Clusters of synapses drive neuronal activity more strongly when activated synchronously through nonlinear dendritic integration mechanisms (Major et al., 2013). Neurons that implement synaptic clustering may fire selectively to precise combinations of inputs spatially co-localized on the dendrite, in theory dramatically increasing memory storage capacity (Poirazi and Mel, 2001). Too much input clustering, however, may potentially lead to "overfitting" of learned representations leading to a rigid and restricted behavioral repertoire that may not be flexible enough to accommodate the efficient learning of new representations (Collins et al., 2004; Na et al., 2012; Cai et al., 2020; 
Yu et al., 2020). Changes in input clustering could also contribute to changes in neuronal network correlation structure, excitability, and sensory processing (Lu et al., 2016; Nageshappa et al., 2016; Zhang et al., 2017; Zhou et al., 2019; Sun et al., 2020). We note that the above discussion depends on functional as well as cytological clustering of synaptic inputs, while at this point, we only show differences in cytological clustering of newly formed spines in MECP2-dupication mice.

\section{Presynaptic inputs}

It is interesting to speculate on the origins of the presynaptic inputs to the newly-formed corticospinal apical-tuft dendritic spines we studied. Corticospinal neurons integrate information from premotor cortex, somatosensory cortex, and corticostriatal and corticocerebellar circuits to implement adaptive motor control (Kuramoto et al., 2009; Mao et al., 2011; Hooks et al., 2013). Previous work showed increased stability of presynaptic axonal boutons in L5 pyramidal neuron projections to layer 1 of motor cortex in mutant mice (Ash et al., 2018). This raises the possibility that these boutons could form synapses with newly formed spines, increasing the stability of the boutonspine complex in MECP2-duplication mice. An interesting nonexclusive possibility is that newly formed synaptic clusters reflect multiple synaptic connections from a single presynaptic neuron (Kasthuri et al., 2015; Yang et al., 2016).

\section{Candidate mechanism of increased clustering}

The molecular mechanisms driving increased clustered spine stabilization in mutants is a fascinating research question. Of particular interest is the Ras-MAPK pathway, which has been shown in vitro to be specifically involved in the cooperative potentiation of neighboring dendritic spines (Harvey et al., 2008; Patterson et al., 2010; Kwon and Sabatini, 2011). Ras-MAPK genes are dysregulated in MECP2-duplication mice (Chahrour et al., 2008), mutations in Ras-MAPK pathway genes are linked to several forms of autism (Stornetta and Zhu, 2011), and several autism models have been shown to have abnormal RasMAPK signaling (Ebert and Greenberg, 2013).

\section{Effects of training}

We note that training on the rotarod did not lead to increased spine formation, stabilization or clustering in either genotype, nor did the number of spines stabilized during learning correlate strongly with motor performance separately for each genotype, in contrast to prior studies (Yang et al., 2009; Fu et al., 2012; Liston et al., 2013; Clark et al., 2018; Frank et al., 2018). We believe that the absence of a strong link between spine stabilization/clustering and motor learning within genotype is because of the fact that we employed a weak rotarod training paradigm of four trials per day for $4 d$ (vs 20 trials per day for $2 d$ as in Yang et al., 2009). Our paradigm was designed to maximize the behavioral difference between mutants and controls (as in Collins et al., 2004 and Sztainberg et al., 2015), but was not as effective in eliciting changes in spine formation or stabilization above the baseline observed without training. It is likely that repeated "overtraining" in a task is necessary to induce measurable increases in spine formation in area M1. Future work with stronger or different training paradigms (e.g., the seed-grabbing task in Fu et al., 2012) will allow a better controlled assessment of the relationship between enhanced clustered spine stabilization and enhanced motor learning in MECP2-duplication mice (Collins et al., 2004).

Because of its relative weakness, our paradigm did not elicit significant correlations between spine formation/stabilization and motor performance within each genotype. It did demonstrate a strong correlation between the propensity for spine stabilization (measured regardless of training) and motor performance, when genotypes were pooled together (Figs. 1/, 3F). Interestingly, this correlation was mediated entirely by spines that formed in clusters and not by the formation of new isolated spines (Fig. $3 F, G)$. This observation suggests a link between the capacity to form spine clusters and behavioral performance (Frank et al., 2018). However, it remains an open question whether enhanced motor performance in MECP2-duplication animals is in fact causally because of their increased capacity for synaptic clustering.

Our findings illustrate how neural circuit analysis can generate new hypotheses about the pathophysiology of neurodevelopmental disorders. We demonstrated a marked increase in clustering of newly formed spines in MECP2-duplication animals, which occurs regardless of training and appears to be associated with the enhanced capacity for motor learning observed early-on in these animals. It remains an open question whether increased clustered-spine stability contributes causally to the motor phenotype of the mouse model of MECP2-duplication syndrome. It is also not clear whether/how the observed synaptic stability phenotype may contribute to some aspects of the human disorder. In the future, it will be valuable to explore further the proposition that a pathologic imbalance between synaptic stability and plasticity in different circuits might account for different phenotypic aspects of the MECP2-duplication syndrome and other autism spectrum disorders.

\section{References}

Alexander BH, Barnes HM, Trimmer E, Davidson AM, Ogola BO, Lindsey SH, Mostany R (2018) Stable density and dynamics of dendritic spines of cortical neurons across the estrous cycle while expressing differential levels of sensory-evoked plasticity. Front Mol Neurosci 11:83.

Ash RT, Fahey PG, Park J, Zoghbi HY, Smirnakis SM (2018) Increased axonal bouton stability during learning in the mouse model of MECP2 duplication syndrome. eNeuro 5:ENEURO.005617.2018.

Bernard C (2019) Changing the way we report, interpret, and discuss our results to rebuild trust in our research. eNeuro 6:ENEURO. 0259-19.2019.

Cai DC, Wang Z, Bo T, Yan S, Liu Y, Liu Z, Zeljic K, Chen X, Zhan Y, Xu X, Du Y, Wang Y, Cang J, Wang GZ, Zhang J, Sun Q, Qu Z, Ge $S$, Ye Z, Wang Z (2020) MeCP2 duplication causes aberrant GABA pathways, circuits and behaviors in transgenic monkeys: neural mappings to patients with autism. J Neurosci 40:3799-3814. 
Calin-Jageman RJ, Cumming G (2019) Estimation for better inference in neuroscience. eNeuro 6:ENEURO.0205-19.2019.

Chahrour M, Zoghbi HY (2007) The story of Rett syndrome: from clinic to neurobiology. Neuron 56:422-437.

Chahrour M, Sung YJ, Shaw C, Zhou X, Wong STC, Qin J, Zoghbi HY (2008) MeCP2, a key contributor to neurological disease, activates and represses transcription. Science 320:1224-1229.

Chow DK, Groszer M, Pribadi M, Machniki M, Carmichael ST, Liu X, Trachtenberg JT (2009) Laminar and compartmental regulation of dendritic growth in mature cortex. Nat Neurosci 12:116-118.

Clark TA, Fu M, Dunn AK, Zuo Y, Jones TA (2018) Preferential stabilization of newly formed dendritic spines in motor cortex during manual skill learning predicts performance gains, but not memory endurance. Neurobiol Learn Mem 152:50-60.

Collins AL, Levenson JM, Vilaythong AP, Richman R, Armstrong DL, Noebels JL, Sweatt JD, Zoghbi HY (2004) Mild overexpression of MeCP2 causes a progressive neurological disorder in mice. Hum Mol Genet 13:2679-2689.

Cruz-Martín A, Crespo M, Portera-Cailliau C (2010) Delayed stabilization of dendritic spines in fragile X mice. J Neurosci 30:77937803.

Ebert DH, Greenberg ME (2013) Activity-dependent neuronal signalling and autism spectrum disorder. Nature 493:327-337.

Feng G, Mellor RH, Bernstein M, Keller-Peck C, Nguyen QT, Wallace M, Nerbonne JM, Lichtman JW, Sanes JR (2000) Imaging neuronal subsets in transgenic mice expressing multiple spectral variants of GFP. Neuron 28:41-51.

Frank AC, Huang S, Zhou M, Gdalyahu A, Kastellakis G, Silva TK, Lu E, Wen X, Poirazi P, Trachtenberg JT, Silva AJ (2018) Hotspots of dendritic spine turnover facilitate clustered spine addition and learning and memory. Nat Commun 9:422.

Fu M, Yu X, Lu J, Zuo Y (2012) Repetitive motor learning induces coordinated formation of clustered dendritic spines in vivo. Nature 483:92-96.

Gdalyahu A, Lazaro M, Penagarikano O, Golshani P, Trachtenberg JT, Gescwind DH (2015) The autism related protein contactin-associated protein-like 2 (CNTNAP2) stabilizes new spines: an in vivo mouse study. PLoS One 10:e0125633.

Gökçe O, Bonhoeffer T, Scheuss V (2016) Clusters of synaptic inputs on dendrites of layer 5 pyramidal cells in mouse visual cortex. Elife 5:e09222.

Grimsley CA, Sanchez JT, Sivaramakrishnan S (2013) Midbrain local circuits shape sound intensity codes. Front Neural Circuits 7:174.

Harvey CD, Svoboda K (2007) Locally dynamic synaptic learning rules in pyramidal neuron dendrites. Nature 450:1195-1200.

Harvey CD, Yasuda R, Zhong H, Svoboda K (2008) The spread of Ras activity triggered by activation of a single dendritic spine. Science 321:136-140.

Ho J, Tumkaya T, Aryal S, Choi H, Claridge-Chang A (2019) Moving beyond $p$ values: data analysis with estimation graphics. Nat Methods 16:565-566.

Holtmaat A, Wilbrecht L, Knott GW, Welker E, Svoboda K (2006) Experience-dependent and cell-type-specific spine growth in the neocortex. Nature 441:979-983.

Holtmaat A, Bonhoeffer T, Chow DK, Chuckowree J, De Paola V, Hofer SB, Hübener M, Keck T, Knott G, Lee WCA, Mostany R, Mrsic-Flogel TD, Nedivi E, Portera-Cailliau C, Svoboda K, Trachtenberg JT, Wilbrecht L (2009) Long-term, high-resolution imaging in the mouse neocortex through a chronic cranial window. Nat Protoc 4:1128-1144.

Hooks BM, Mao T, Gutnisky DA, Yamawaki N, Svoboda K, Shepherd GMG (2013) Organization of cortical and thalamic input to pyramidal neurons in mouse motor cortex. J Neurosci 33:748-760.

Howlin P, Goode S, Hutton J, Rutter M (2009) Savant skills in autism: psychometric approaches and parental reports. Philos Trans R Soc Lond B Biol Sci 364:1359-1367.

Isshiki M, Tanaka S, Kuriu T, Tabuchi K, Takumi T, Okabe S (2014) Enhanced synapse remodelling as a common phenotype in mouse models of autism. Nat Commun 5:4742.
Jiang M, Ash RT, Baker SA, Suter B, Ferguson A, Park J, Rudy J, Torsky SP, Chao HT, Zoghbi HY, Smirnakis SM (2013) Dendritic arborization and spine dynamics are abnormal in the mouse model of MECP2 duplication syndrome. J Neurosci 33:19518-19533.

Kastellakis G, Cai DJ, Mednick SC, Silva AJ, Poirazi P (2015) Synaptic clustering within dendrites: an emerging theory of memory formation. Prog Neurobiol 126:19-35.

Kasthuri N, Hayworth KJ, Berger DR, Schalek RL, Conchello JA, Knowles-Barley S, Lee D, Vázquez-Reina A, Kaynig V, Jones TR, Roberts M, Morgan JL, Tapia JC, Seung HS, Roncal WG, Vogelstein JT, Burns R, Sussman DL, Priebe CE, Pfister H, et al. (2015) Saturated reconstruction of a volume of neocortex. Cell 162:648-661.

Knott GW, Holtmaat A, Wilbrecht L, Welker E, Svoboda K (2006) Spine growth precedes synapse formation in the adult neocortex in vivo. Nat Neurosci 9:1117-1124.

Kuramoto E, Furuta T, Nakamura KC, Unzai T, Hioki H, Kaneko T (2009) Two types of thalamocortical projections from the motor thalamic nuclei of the rat: a single neuron-tracing study using viral vectors. Cereb Cortex 19:2065-2077.

Kwon HB, Sabatini BL (2011) Glutamate induces de novo growth of functional spines in developing cortex. Nature 474:100-104.

Landi S, Putignano E, Boggio EM, Giustetto M, Pizzorusso T, Ratto GM (2011) The short-time structural plasticity of dendritic spines is altered in a model of Rett syndrome. Sci Rep 1:45.

Liston C, Cichon JM, Jeanneteau F, Jia Z, Chao MV, Gan WB (2013) Circadian glucocorticoid oscillations promote learning-dependent synapse formation and maintenance. Nat Neurosci 16:698-705.

Lu H, Ash RT, He L, Kee SE, Wang W, Yu D, Hao S, Meng X, Ure K, Ito-Ishida A, Tang B, Sun Y, Ji D, Tang J, Arenkiel BR, Smirnakis SM, Zoghbi HY (2016) Loss and gain of MeCP2 cause similar hippocampal circuit dysfunction that is rescued by deep brain stimulation in a Rett syndrome mouse model. Neuron 91:739-747.

Lyst MJ, Bird A (2015) Rett syndrome: a complex disorder with simple roots. Nat Rev Genet 16:261-274.

Major G, Larkum ME, Schiller J (2013) Active properties of neocortical pyramidal neuron dendrites. Annu Rev Neurosci 36:1-24.

Mao T, Kusefoglu D, Hooks BM, Huber D, Petreanu L, Svoboda K (2011) Long-range neuronal circuits underlying the interaction between sensory and motor cortex. Neuron 72:111-123.

Morita K (2009) Computational implications of cooperative plasticity induction at nearby dendritic sites. Sci Signal 2:p2.

Mostany R, Portera-Cailliau C (2008) A craniotomy surgery procedure for chronic brain imaging. J Vis Exp. Advance online publication. Retrieved February 15, 2008. doi:10.3791/680.

Mostany R, Portera-Cailliau C (2011) Absence of large-scale dendritic plasticity of layer 5 pyramidal neurons in peri-infarct cortex. $J$ Neurosci 31:1734-1738.

Na ES, Nelson ED, Adachi M, Autry AE, Mahgoub MA, Kavalali ET, Monteggia LM (2012) A mouse model for MeCP2 duplication syndrome: MeCP2 overexpression impairs learning and memory and synaptic transmission. J Neurosci 32:3109-3117.

Nageshappa S, Carromeu C, Trujillo CA, Mesci P, Espuny-Camacho I, Pasciuto E, Vanderhaeghen P, Verfaillie CM, Raitano S, Kumar A, Carvalho CMB, Bagni C, Ramocki MB, Araujo BHS, Torres LB, Lupski JR, Van Esch H, Muotri AR (2016) Altered neuronal network and rescue in a human MECP2 duplication model. Mol Psychiatry 21:178-188.

Padmashri R, Reiner BC, Suresh A, Spartz E, Dunaevsky A (2013) Altered structural and functional synaptic plasticity with motor skill learning in a mouse model of fragile $X$ syndrome. $J$ Neurosci 33:19715-19723.

Patterson MA, Szatmari EM, Yasuda R (2010) AMPA receptors are exocytosed in stimulated spines and adjacent dendrites in a RasERK-dependent manner during long-term potentiation. Proc Natl Acad Sci USA 107:15951-15956.

Peters SU, Hundley RJ, Wilson AK, Warren Z, Vehorn A, Carvalho CMB, Lupski JR, Ramocki MB (2013) The behavioral phenotype in MECP2 duplication syndrome: a comparison with idiopathic autism. Autism Res 6:42-50. 
Poirazi P, Mel BW (2001) Impact of active dendrites and structural plasticity on the memory capacity of neural tissue. Neuron 29:779796.

Ramocki MB, Zoghbi HY (2008) Failure of neuronal homeostasis results in common neuropsychiatric phenotypes. Nature 455:912918.

Ramocki MB, Peters SU, Tavyev YJ, Zhang F, Carvalho CMB, Schaaf CP, Richman R, Fang P, Glaze DG, Lupski JR, Zoghbi HY (2009) Autism and other neuropsychiatric symptoms are prevalent in individuals with MECP2 duplication syndrome. Ann Neurol 66:771-782

Ramocki MB, Tavyev YJ, Peters SU (2010) The MECP2 duplication syndrome. Am J Med Genet A 152A:1079-1088.

Reiner BC, Dunaevsky A (2015) Deficit in motor training-induced clustering, but not stabilization, of new dendritic spines in fmr1 knock-out mice. PLoS One 10:e0126572.

Samaco RC, Mandel-Brehm C, McGraw CM, Shaw CA, McGill BE, Zoghbi HY (2012) Crh and Oprm1 mediate anxiety-related behavior and social approach in a mouse model of MECP2 duplication syndrome. Nat Genet 44:206-221.

Stornetta RL, Zhu JJ (2011) Ras and Rap signaling in synaptic plasticity and mental disorders. Neuroscientist 17:54-78.

Sun L, Chen R, Li L, Yuan B, Song K, Pan N, Cheng TL, Chang S, Lin K, He X, Wu Q, Xu F, Qiu Z, Wang X (2020) Visualization and correction of social abnormalities-associated neural ensembles in adult MECP2 duplication mice. Sci Bull 65:1192-1202.

Sztainberg Y, Chen HM, Swann JW, Hao S, Tang B, Wu Z, Tang J, Wan YW, Liu Z, Rigo F, Zoghbi HY (2015) Reversal of phenotypes in MECP2 duplication mice using genetic rescue or antisense oligonucleotides. Nature 528:123-126.

Tennant KA, Adkins DL, Donlan NA, Asay AL, Thomas N, Kleim JA, Jones TA (2011) The organization of the forelimb representation of the C57BL/6 mouse motor cortex as defined by intracortical microstimulation and cytoarchitecture. Cereb Cortex 21:865-876.

Tordjman S, Drapier D, Bonnot O, Graignic R, Fortes S, Cohen D, Millet B, Laurent C, Roubertoux PL (2007) Animal models relevant to schizophrenia and autism: validity and limitations. Behav Genet 37:61-78.

Treffert DA (2014) Savant syndrome: realities, myths and misconceptions. J Autism Dev Disord 44:564-571.

Weber JP, Andrásfalvy BK, Polito M, Magó Á, Ujfalussy BB, Makara JK (2016) Location-dependent synaptic plasticity rules by dendritic spine cooperativity. Nat Commun 7:11380.

Yang G, Pan F, Gan WB (2009) Stably maintained dendritic spines are associated with lifelong memories. Nature 462:920-924.

Yang Y, Liu DQ, Huang W, Deng J, Sun Y, Zuo Y, Poo MM (2016) Selective synaptic remodeling of amygdalocortical connections associated with fear memory. Nat Neurosci 19:1348-1355.

Yu B, Yuan B, Dai JK, lin Cheng T, Xia SN, He LJ, Yuan YT, Zhang YF, Xu HT, Xu FQ, Liang ZF, Qiu ZL (2020) Reversal of social recognition deficit in adult mice with MECP2 duplication via normalization of MeCP2 in the medial prefrontal cortex. Neurosci Bull 36:570-584.

Zhang D, Yu B, Liu J, Jiang W, Xie T, Zhang R, Tong D, Qiu Z, Yao H (2017) Altered visual cortical processing in a mouse model of MECP2 duplication syndrome. Sci Rep 7:6468.

Zhou C, Yan S, Qian S, Wang Z, Shi Z, Xiong Y, Zhou Y (2019) Atypical response properties of the auditory cortex of awake MECP2-overexpressing mice. Front Neurosci 13:439.

Zuo Y, Lin A, Chang P, Gan WB (2005) Development of long-term dendritic spine stability in diverse regions of cerebral cortex. Neuron 46:181-189. 